\title{
Efficacy of Oral Itraconazole in the Treatment of Seborrheic Dermatitis
}

\author{
L KHONDKER $^{\mathrm{a}}$, AM CHOUDHURY ${ }^{\mathrm{b}}$, MA WAHAB $^{\mathrm{c}}$, MSI KHAN $^{\mathrm{d}}$
}

\begin{abstract}
Summary:
Background: Seborrheic dermatitis is a common papulosquamous dermatosis and occurring in $2 \%$ to $5 \%$ of the population. The prevalence of seborrheic dermatitis among HIV-positive and AIDS patients between $34 \%$ and $83 \%$. The anti-inflammatory activity of oral itraconazole and efficacy on Malessezia suggests that itraconazole capsule will be the first oral treatment option in future in seborrheic dermatitis. Unfortunately there is no data base study with the efficacy of oral itraconazole for the treatment of seborrheic dermatitis over Bangladeshi people.
\end{abstract}

Objectives: To evaluate the efficacy of itraconazole in the treatment of Seborrheic dermatitis.

Methods: This was an interventional type of study and total thirty seven patients of seborrheic dermatitis from department of Dermatology and Venereology, Bangabandhu Sheikh Mujib Medical University (BSMMU) was enrolled. The study was carried out for a period of two years from January 2008 to December 2009 and purposive type non-probability sampling technique was followed in this study.

Results: The scoring of seborrhea was $6.33 \pm 1.15$ before treatment and $4.33 \pm 3.21$ after treatment, scoring of itching was $6.66 \pm 1.49$ before treatment and $3.61 \pm 2.70$ after

Introduction:

Seborrheic dermatitis is a common papulo- squamous dermatosis, present in an estimated $15-20 \%$ of the population. ${ }^{1}$ It is a chronic, superficial, inflammatory disease with a predilection for the scalp, eyebrows, eyelids, naso-labial creases, ears, axilla, submammary

a. Dr. Lubna Khondker, FCPS (Dermatology and Venereology).

b. Professor. A. Masood Choudhury, MS (Dermatology and Venereology)

c. Lt Col. (Retd) Dr. Md Abdul Wahab, FCPS (Dermatology and Venereology)

d. Major (Dr). Md Shirajul Islam Khan, Trainee of Dermatology and Venereology.

Address of Correspondence: Dr. Lubna Khondker, FCPS (Dermatology and Venereology), Assistant Professor, Department of Medical Statistics, Bangabandhu Sheikh Mujib Medical University (BSMMU), Shahbag, Dhaka, Bangladesh, Mobile- 01552370429, E-mail: lubna_derma@yahoo.com.

Received: 18 October 2010

Accepted: 20 September 2011 treatment and scoring of greasy crust was $7.12 \pm 2.70$ before treatment and $4.00 \pm 3.16$ after treatment. It was observed that before treatment, erythema was severe in $43.2 \%$ cases, moderate in $51.4 \%$ cases and mild type erythema was present in $5.4 \%$ cases. And after treatment, 29.7\% had severe type erythema, no patient had moderate type erythema, only $43.2 \%$ had mild type and $27 \%$ cases had no erythema at all. Before treatment, papular eruption was severe in $27 \%$ cases, moderate in $54.1 \%$ cases and only $18.9 \%$ had mild type papular eruption. But after treatment, $10.8 \%$ had severe type, $18.9 \%$ had moderate, $51.4 \%$ had mild and $18.9 \%$ had no papular eruption at all. It was observed that before treatment, squamation was severe in $37.8 \%$ cases and moderate in $62.2 \%$ cases. But after treatment, $18.9 \%$ had severe type squamation, $10.8 \%$ had moderate, $45.9 \%$ had mild and $24.3 \%$ had no squamation. Improvement was shown in 26(70.27\%) cases and 11(29.73\%) cases shown no improvement at all.

Conclusion: The study suggests that oral itraconazole has significant efficacy profile for treatment option of seborrheic dermatitis.

Key words: Itraconazole, Seborrheic dermatitis, Efficacy.

(J Bangladesh Coll Phys Surg 2011; 29: 201-206)

folds, umbilicus, groins and gluteal creases. The disease is characterized by scaling on an erythematous base. The scale often has a yellow, greasy appearance. Itching may be severe. In extreme cases a greasy, dirty crust with an offensive odor covers the entire scalp. ${ }^{2}$ The cause of seborrheic dermatitis is unknown; Immunological, nutritional, environmental and lifestyle factors that might increase the predisposition to seborrheic dermatitis. ${ }^{3}$ The prevalence of seborrheic dermatitis among HIV-positive and AIDS patients between $34 \%$ and $83 \%$. Seborrheic dermatitis in HIVpositive and AIDS patients is more severe than the usual immune deficiencies. ${ }^{4}$ Seborrheic dermatitis is also associated with chronic alcoholic pancreatitis, hepatitis $\mathrm{C}$ virus and various cancers. It is also common in patients with genetic disorders, Hailey-Hailey disease and cardio -facio-cutaneous syndrome. Arsenic, gold, methyldopa, cimetidine, and narcoleptics drugs, post encephalitic parkinsonism, epilepsy, supraorbital injury, facial 
paralysis, poliomyelitis, syringomyelia, and quadriplegia; low fall and winter temperatures and low humidity and psoriasis; biotin deficiency, and abnormal metabolism of essential fatty acids have been proposed as possible mechanisms. ${ }^{1}$ Diseases associated with Malassezia spp. are also commonly found in patients with seborrheic dermatitis, these include pityriasis versicolor and pityrosporum folliculitis. ${ }^{4}$ Patients with seborrhoeic dermatitis may show upregulation of interferon (IFN)-g, expressed interleukin (IL)-6, expressed-IL-1a, and IL-4. Expressions of cytotoxicity activating ligands and recruitment of natural killer (NK) cells have also been noted. ${ }^{2}$ Itraconazole is a lipophilic and keratophilic systemic antifungal agent. Seborrheic dermatitis shows marked reduction in inflammation when treated with itraconazole. It suppresses the random movement and chemotaxis of neutrophil via inhibition of interleukin- 8 production in epidermal keratinocytes. ${ }^{5}$ The anti-inflammatory activity of oral itraconazole and efficacy on Malessezia suggests that itraconazole capsule will be the first oral treatment option in future in seborrheic dermatitis. Its high lipophilicity means that it persists in the skin and appendages above the therapeutic concentration for some weeks even after the cessation of therapy (reservoir effect). This dual antifungal and anti-inflammatory effect may account for the prolong therapeutic action of low dose itraconazole. ${ }^{6}$ Unfortunately there is no data base study with the efficacy of oral itraconazole for the treatment of seborrheic dermatitis over Bangladeshi people. Limited information is available regarding this. Here, an endeavor had been made to do such a study.

\section{Materials and Methods:}

The interventional study was carried out for a period of total two years from January 2008 to December 2009 in the department of Dermatology and Venereology, Bangabandhu Sheikh Mujib Medical University (BSMMU), Dhaka in Bangladesh. Total thirty seven patients of seborrheic dermatitis were selected considering exclusion criteria like patient with known hypersensitivity to any ingredients of the itraconazole, pregnancy/ lactation, impaired hepatic function, impaired renal function and severe systemic illness. The inclusion criteria of patient selection were include both male and female patient of any age, patient willing to give consent to take part in the study, patient expected to be available for the duration of study and able to comply with the study visit and patient received no topical treatment for 2 weeks prior to the study and no systemic antifungal intake. Purposive type nonprobability sampling technique was followed in this study. After collection of data, these were screened by checking consistency, edited and were finally analyzed by software SPSS (Statistical Package for Social Science) method.

Procedure of Treatment: All patients with seborrheic dermatitis were treated by oral itraconazole capsule (200 $\mathrm{mg}$ / day X 7 days) in first month and consecutive usage $200 \mathrm{mg} /$ day for the first 2 days of the following 11 months. Skin involvement before and after therapy was assessed by a clinical score based on the involvement of different grades of erythema, papular eruption and squamation(scale). On the initial evaluation, the patients were examined at three sites- scalp, face and chest and graded numerically at each site for erythema, papular eruption and squamation/scale: $0=$ normal, $1=$ mild, $2=$ moderate and $3=$ severe for all. Skin lesions were inspected with respect to diameter and color. The area of involvement were measured on a scale of 1 to 5 . Scale $1=$ less than $10 \%, 2=11 \%-30 \%, 3=31 \%-50 \%, 4=51 \%$ $70 \%$ and $5=$ more than $70 \%$ area involvement. The final assessment of the total improvement were made after 12 months. Response to therapy were rated as excellent when $>75 \%$ improvement; good when $50-75 \%$ clearing; fair when $25-50 \%$ clearing and poor when $<25 \%$ clearing of skin lesion occurred.

\section{Results:}

Total thirty seven patients of seborrheic dermatitis from the department of Dermatology and Venereology, Bangabandhu Sheikh Mujib Medical University (BSMMU) were subjected to this study. Table I showed that scoring of seborrhea was $6.33 \pm 1.15$ before treatment and $4.33 \pm 3.21$ after treatment, scoring of itching was $6.66 \pm 1.49$ before treatment and $3.61 \pm 2.70$ after treatment and scoring of greasy crust was 7.12 \pm 2.70 before treatment and $4.00 \pm 3.16$ after treatment. Table II showed the distribution of patients of seborrheic dermatitis by grading of erythema, papular eruption and squamation, before and after treatment by drug. It was observed that before treatment, erythema was severe in $43.2 \%$ cases, moderate in $51.4 \%$ cases and mild type erythema was present in $5.4 \%$ cases. And after treatment, $29.7 \%$ had severe type erythema, no patient had 
Table I

Relationship between complaints and scoring in before and after treatment ( $n=37)$.

\begin{tabular}{lcccc} 
Complaints & \multicolumn{2}{c}{ Before treatment } & \multicolumn{2}{c}{ After treatment } \\
& No & Mean \pm SD & No & Mean \pm SD \\
\hline Seborrhoea & 3 & $6.33 \pm 1.15$ & 3 & $4.33 \pm 3.21$ \\
Itching & 18 & $6.66 \pm 1.49$ & 18 & $3.61 \pm 2.70$ \\
Greasy crust & 16 & $7.12 \pm 2.70$ & 16 & $4.00 \pm 3.16$ \\
\hline
\end{tabular}

\section{Table II}

\begin{tabular}{lccc}
\multicolumn{5}{c}{$\begin{array}{c}\text { Distribution of patients by grading of erythema, papular eruption and squamation before } \\
\text { and after treatment by }\end{array}$} \\
& Bsing drug $(n=37)$. \\
\hline Erythema & Before treatment & After treatment \\
\hline & Mild & $0(00)$ & $10(27)$ \\
& Moderate & $2(5.4)$ & $16(43.2)$ \\
Papular eruption & Severe & $19(51.4)$ & $0(00)$ \\
& Normal & $16(43.2)$ & $11(29.7)$ \\
& Mild & $0(00)$ & $10(27)$ \\
Squamation & Moderate & $7(18.9)$ & $16(43.2)$ \\
& Severe & $20(51.4)$ & $0(00)$ \\
& Normal & $16(43.2)$ & $11(29.7)$ \\
& Mild & $0(00)$ & $10(27)$ \\
& Moderate & $2(5.4)$ & $16(43.2)$ \\
& Severe & $19(51.4)$ & $0(00)$ \\
& & $16(43.2)$ & $11(29.7)$ \\
\hline
\end{tabular}

moderate type erythema, only $43.2 \%$ had mild type and $27 \%$ cases had no erythema at all. Before treatment, papular eruption was severe in $27 \%$ cases, moderate in $54.1 \%$ cases and only $18.9 \%$ had mild type papular eruption. But after treatment, $10.8 \%$ had severe type , $18.9 \%$ had moderate, $51.4 \%$ had mild and $18.9 \%$ had no papular eruption at all. It was observed that before treatment, squamation was severe in $37.8 \%$ cases and moderate in $62.2 \%$ cases. But after treatment, $18.9 \%$ had severe type squamation, $10.8 \%$ had moderate, $45.9 \%$ had mild and $24.3 \%$ had no squamation. From Table III it was observed that when complaint was seborrhea, level of erythema was moderate 1 and severe 2 before treatment and after treatment, was normal 1, mild 1 and severe 1, when complaint was itching, level of erythema was mild 2, moderate 9 and severe 7 before treatment and after treatment, level of erythema was normal 9, mild 4 and severe 5, when complaint was greasy crust, level of erythema was moderate 9 and severe 7 before treatment and after treatment, mild 11 and severe 5. It was observed that when complaint was seborrhea, level of papular eruption was mild 1 , and moderate 2 before treatment and after treatment, level of papular eruption was mild 2 , and moderate 1 . When complaint was itching, level of papular eruption was mild 5 , moderate 8 and severe 5 before treatment and after treatment, level of papular eruption was normal 3, mild 10, moderate 3 and severe 2 . When complaint was greasy crust, level of papular eruption was mild 1, moderate 10 and severe 5 before treatment and after treatment, level of papular eruption was normal 4, mild 7 , moderate 3 and severe 2 . And it was observed that when complaint was seborrhea, level of squamation was moderate 3 before treatment and after treatment, was mild 2 and moderate 1 . When complaint was itching, level of squamation was moderate 11 and severe 7 before 
Table-III

Relationship between complaints and clinical finding in before and after treatment by drugs $(n=37)$.

\begin{tabular}{|c|c|c|c|c|c|c|c|c|c|}
\hline \multirow[b]{2}{*}{ Erythema } & \multirow[b]{2}{*}{ Complaints } & \multicolumn{4}{|c|}{ Before treatment } & \multicolumn{4}{|c|}{ After treatment } \\
\hline & & Normal & Mild & Moderate & Severe & Normal & Mild & Moderate & Severe \\
\hline & Seborrhoea & 0 & 0 & 1 & 2 & 1 & 1 & 0 & 1 \\
\hline & Itching & 0 & 2 & 9 & 7 & 9 & 4 & 0 & 5 \\
\hline & Greasy crust & 0 & 0 & 9 & 7 & 0 & 11 & 0 & 5 \\
\hline & Total & 0 & 2 & 19 & 16 & 10 & 16 & 0 & 11 \\
\hline \multirow{5}{*}{$\begin{array}{l}\text { Papular } \\
\text { eruption }\end{array}$} & Complaints & Normal & Mild & Moderate & Severe & Normal & Mild & Moderate & Severe \\
\hline & Seborrhoea & 0 & 1 & 2 & 0 & 0 & 2 & 1 & 0 \\
\hline & Itching & 0 & 5 & 8 & 5 & 3 & 10 & 3 & 2 \\
\hline & Greasy crust & 0 & 1 & 10 & 5 & 4 & 7 & 3 & 2 \\
\hline & Total & 0 & 7 & 20 & 10 & 7 & 19 & 7 & 4 \\
\hline \multirow[t]{5}{*}{ Squamation } & Complaints & Normal & Mild & Moderate & Severe & Normal & Mild & Moderate & Severe \\
\hline & Seborrhoea & 0 & 0 & 3 & 0 & & 2 & 1 & \\
\hline & Itching & 0 & 0 & 11 & 7 & 3 & 10 & 3 & 2 \\
\hline & Greasy crust & 0 & 0 & 9 & 7 & 6 & 5 & 0 & 5 \\
\hline & Total & 0 & 0 & 23 & 14 & 9 & 17 & 4 & 7 \\
\hline
\end{tabular}

treatment and after treatment, level of squamation was normal 3, mild 10, moderate 3 and severe 2 and when complaint was greasy crust, level of squamation was moderate 9 and severe 7 before treatment and after treatment, level of squamation was normal 6 , mild 5 and severe 5. Figure I showed the level of improvement

Improved

Not improved

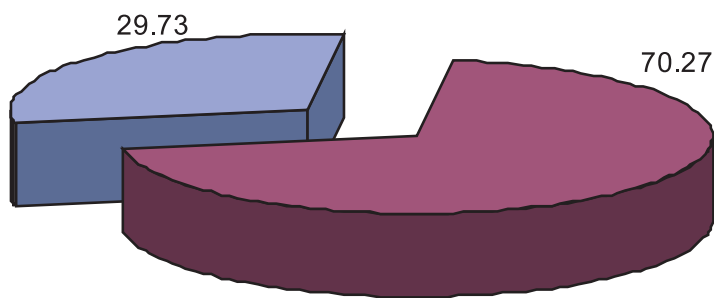

Fig.-1: Distribution of patients by level of improvement by using drug $(N=37)$ by drugs among 37 patients of seborrheic dermatitis. Improvement was shown in $26(70.27 \%)$ cases and $11(29.73 \%)$ cases shown no improvement at all. Statistical test was done and found significant $(\mathrm{p}<05)$. In table IV improvement observed on the $1^{\text {st }}$ follow up visit at the end of 6 weeks. Response was fair 10 (38.46\%) cases and poor $16(61.54 \%)$ cases and marked improvement observed on the $2^{\text {nd }}$ follow up visit at the end of 12 weeks-response was good in $23(88.46 \%)$ cases, fair $2(7.69 \%)$ and poor $1(3.85 \%)$ cases.

\section{Table IV}

Distribution of response of treatment by using drug at different weeks $(N=37)$.

\begin{tabular}{lcc} 
Response & $\begin{array}{c}6 \text { weeks of } \\
\text { treatment }\end{array}$ & $\begin{array}{c}12 \text { weeks of } \\
\text { treatment }\end{array}$ \\
\hline Excellent & 0 & 0 \\
Good & 0 & $23(88.46 \%)$ \\
Fair & $10(38.46 \%)$ & $2(7.69 \%)$ \\
Poor & $16(61.54 \%)$ & $1(3.85 \%)$ \\
\hline
\end{tabular}




\section{Discussion:}

This interventional type of study carried out to evaluate the efficacy of itraconazole in the treatment of Seborrheic dermatitis. Total 37 patients of seborrheic dermatitis were subjected to this study. The scoring of seborrhea was $6.33 \pm 1.15$ before treatment and 4.33 \pm 3.21 after treatment, scoring of itching was $6.66 \pm 1.49$ before treatment and $3.61 \pm 2.70$ after treatment and scoring of greasy crust was $7.12 \pm 2.70$ before treatment and $4.00 \pm 3.16$ after treatment, similar to the study of Kose et al and Baysal et al. ${ }^{5,6}$ It was observed that before treatment, erythema was severe in $43.2 \%$ cases, moderate in $51.4 \%$ cases and mild type erythema was present in $5.4 \%$ cases. And after treatment, $29.7 \%$ had severe type erythema, no patient had moderate type erythema, only $43.2 \%$ had mild type and $27 \%$ cases had no erythema at all. Before treatment, papular eruption was severe in $27 \%$ cases, moderate in $54.1 \%$ cases and only $18.9 \%$ had mild type papular eruption. But after treatment, $10.8 \%$ had severe type, $18.9 \%$ had moderate, $51.4 \%$ had mild and $18.9 \%$ had no papular eruption at all. It was observed that before treatment, squamation was severe in $37.8 \%$ cases and moderate in $62.2 \%$ cases. But after treatment, $18.9 \%$ had severe type squamation, $10.8 \%$ had moderate, $45.9 \%$ had mild and $24.3 \%$ had no squamation, similar to the study of Baysal where initially scaling disappeared and then erythema and papular eruption. ${ }^{6}$

The study showed that score of patients of seborrheic dermatitis, before treatment was $6.83 \pm 1.30$ and after treatment was $3.83 \pm 1.18$ like Kose et al where score of patients of seborrheic dermatitis, before treatment was $10.44 \pm 2.45$ and after treatment was $3.30 \pm 1.90 .^{5}$ Improvement was shown in $26(70.27 \%$ ) cases and $11(29.73 \%)$ cases shown no improvement at all, similar to the study finding of Kose et al where clinical improvement was observed in 23(83\%) patients among the 29 patients and Baysal where improvement was observed in 28(87\%) patient among 32 patients. 5,6

\section{Conclusion:}

It was evidenced that before treatment, erythema was moderate in majority of cases but after treatment, no patient had moderate type erythema, majority had mild type and more than one-fourth cases had no erythema at all. Papular eruption was moderate in majority of cases prior to the treatment but after treatment, half of the patients had mild type and one fifth had no papular eruption at all. It was further observed that before treatment, squamation was moderate in majority of cases. But following treatment, half of the patient had mild type and one-fourth had no squamation at all. Improvement was shown in three- forth cases and oneforth cases shown no improvement at all. Level of improvement was observed on the $1^{\text {st }}$ follow up visit at the end of 6 weeks. Response was fair in one-third cases and poor in halves cases. Marked improvement was noticed on the $2^{\text {nd }}$ follow up visit at the end of 12 weeks. Response was good in three- fourth cases.

\section{Recommendation:}

The study revealed that itraconazole has remarkable efficacy profile for treatment option of seborrheic dermatitis. This was an open and uncontrolled study on a limited number of cases. Further blinded, randomized, placebo-controlled studies are needed to investigate the effectiveness of therapy. As itraconazole is still expensive, cost-effectiveness studies should be performed. If future studies include large sample size with appropriate economical support ensured and study finding would be more reliable.

\section{References:}

1. Freedberg IM, Eisen AZ, Wolff K, Austen KF, Goldsmith LA and Katz SI. Fitzpatrick's Dermatology in General Medicine. $6^{\text {th }}$ edition. The McGraw- Hill Companies; 2003:1198-1204.

2. James WD, Berger TG and Elston D. Andrews' Diseases of the skin- Clinical Dermatology. $10^{\text {th }}$ edition. Saunders Elsevier; 2006:191-192.

3. Gupta AK and Bluhm R. Seborrheic dermatitis. Journal of European Academy of Dermatology and Venereology 2004; 18: $13-26$.

4. Dunic I, Vesic S, Jevtovic DJ. Oral candidiasis and seborrheic dermatitis in HIV infected patients on highly active antiretroviral therapy. HIV Med. 2004 Jan; 5(1): 50-54.

5. Kose O, Erbil H, Gur AR. Oral itraconazole for the treatment of Seborrheic dermatitis: an open, non-comparative trial. Journal of the European Academy of Dermatology and Venereology(JEADV)2008; 19(2): 172-175.

6. Baysal V, Yildirim M, Ozcanli C and Ceyhan M. Itraconazole for the treatment of Seborrheic dermatitis: a new treatment modality. International Society of Dermatology International Journal of Dermatology 2004; 43:63-66.

7. Koca R, Altinyazar HC, Esturk E. Is topical metronidazole effective in seborrheic dermatitis? Adouble blind study. Int J Dermatol. 2003 Aug; 42(8): 632-5 
8. Gupta AK, Bluhm R, Cooper EA, Summerbell RC, Batra R. Seborrheic dermatitis. Dermatol Clin. 2003 Jul; 21(3): 401412 .

9. Hay RJ, Graham-Brown RA." Dandruff and seborrhoeic dermatitis: causes and management ". Clinical and Experimental Dermatology 1997 January ; 22 (1): 3-6

10. Janniger CK, Schwartz RA. "Seborrheic dermatitis". American Family Physician 1995 July; 52 (1): 149-55, 159-60.

11. Nowicki R. "Modern management of dandruff “ (in Polish). Polski Merkuriusz Lekarski 2006 Jan; 20 (115): 121-4.

12. Parry ME, Sharpe GR. "Seborrhoeic dermatitis is not caused by an altered immune response to Malassezia yeast". The British Journal of Dermatology 1998 Aug; 139 (2): 254-63.

13. Schwartz RA, Janusz CA, Janniger CK. "Seborrheic dermatitis: an overview”. American Family Physician 2006 July ; 74 (1): 125-30.
14. Schwartz JR, Rocchetta H, Asawanonda P, Luo F, Thomas JH. Does tachyphylaxis occur in long- term management of scalp seborrheic dermatitis with pyrithione zinc-based treatments? Int J Dermatol. Jan 2009; 48(1):7985. [Medline].

15. Wolverton SE. Comprehensive Dermatologic Drug Therapy. W. B. Saunders Company; 2001: 62-66.

16. Johnson BA and Nunley JR. Treatment of Seborrheic dermatitis. American Academy of Family Physicians 2000; 61:2703-10

17. Elish D, Silverberg NB. Infantile seborrheic dermatitis. May 2006; 77(5): 297- 300. [Medline].

18. Bergbrant IM. Seborrhoeic dermatitis and Pityrosporum ovale: cultural, immunologic and clinical studies. Acta Derm Venereol 1991; Suppl. 167: 10-36 